\title{
RC-6 ribonuclease induces caspase activation, cellular senescence and neuron-like morphology in NT2 embryonal carcinoma cells
}

\author{
GIOU-TENG YIANG ${ }^{1,2 *}$, HSIU-FENG TSAI ${ }^{1 *}$, JER-RONG CHEN $^{3 *}$, PEI-LUN CHOU $^{4,5}$, \\ TSAI-KUN WU ${ }^{6,7}$, HSIAO-CHUN LIU ${ }^{8}$, WEI-JUNG CHANG ${ }^{9}$, \\ LIANG-CHIH LIU ${ }^{3,10}$, HSU-HUNG TSENG ${ }^{11}$ and YUNG-LUEN YU ${ }^{7,9,12}$
}

\begin{abstract}
${ }^{1}$ Department of Emergency Medicine, Taipei Tzu Chi Hospital, Buddhist Tzu Chi Medical Foundation, New Taipei 231; ${ }^{2}$ Department of Emergency Medicine, School of Medicine, Tzu Chi University, Hualien 970; ${ }^{3}$ Department of Surgery, China Medical University Hospital, Taichung 404; ${ }^{4}$ Division of Allergy-Immunology-Rheumatology, Department of Internal Medicine, Saint Mary's Hospital Luodong, Yilan 265; ${ }^{5}$ Department of Internal Medicine, School of Medicine, College of Medicine, Taipei Medical University, Taipei 110; ${ }^{6}$ Division of Renal Medicine, Tungs' Taichung Metroharbor Hospital, Taichung 435; ${ }^{7}$ The Ph.D. program for Cancer Biology and Drug Discovery, China Medical University, Taichung 404; ${ }^{8}$ Department of Nursing, Taipei Tzu Chi Hospital, Buddhist Tzu Chi Medical Foundation, New Taipei 231 ; ${ }^{9}$ Graduate Institute of Cancer Biology and Center for Molecular Medicine, China Medical University, Taichung $404 ;{ }^{10}$ School of Medicine, China Medical University, Taichung 404; ${ }^{11}$ Division of General Surgery, Taichung Hospital, Ministry of Health and Welfare, Taichung 403; ${ }^{2}$ Department of Biotechnology, Asia University, Taichung 413, Taiwan, R.O.C.
\end{abstract}

Received October 24, 2013; Accepted November 25, 2013

DOI: $10.3892 / o r .2014 .3023$

\begin{abstract}
Frog ribonucleases have been demonstrated to have anticancer activities. However, whether RC-6 ribonuclease exerts anticancer activity on human embryonal carcinoma cells remains unclear. In the present study, RC-6 induced cytotoxicity in NT2 cells (a human embryonal carcinoma cell line) and our studies showed that RC-6 can exert anticancer effects and induce caspase- 9 and -3 activities. Moreover, to date, there is no evidence that frog ribonuclease-induced cytotoxicity effects are related to cellular senescence. Therefore, our studies showed that RC-6 can increase p16 and 21 protein levels and induce cellular senescence in NT2 cells. Notably, similar to retinoic acid-differentiated NT2 cells, neuron-like morphology was found on some remaining live cells after RC- 6 treatment. In conclusion, our study is the first to demonstrate that RC-6 can induce cytotoxic effects, caspase- $9 /-3$ activities, cellular senescence and neuron-like morphology in NT2 cells.
\end{abstract}

Correspondence to: Dr Yung-Luen Yu, Graduate Institute of Cancer Biology and Center for Molecular Medicine, China Medical University, Taichung 404, Taiwan, R.O.C.

E-mail: ylyu@mail.cmu.edu.tw

Dr Hsu-Hung Tseng, Division of General Surgery, Taichung Hospital, Ministry of Health and Welfare, Taichung 403, Taiwan, R.O.C.

E-mail: qn3020@yahoo.com.tw

*Contributed equally

Key words: RC-6, caspase, senescence, neuron-like, embryonal carcinoma

\section{Introduction}

Human NTERA-2 D1 cells (NT2 cells) belong to embryonal carcinoma cells that have cancer and stem cell characteristics (1-4). Therefore, NT2 cells are often used as cell models for cancer therapy and neuron differentiation studies (5-7). Currently, cisplatin, fisetin and nucleoside drugs are applied to NT2 cell treatment. These drugs can activate the MAPK and caspase-dependent pathway resulting in NT2 cell death $(8,9)$. On the other hand, NT2 cells can be induced to differentiate into neuron cells by treatment with differentiation agents including retinoic acid, AraC, DAC, valproic acid and berberine $(7,8,10,11)$. Among these differentiation agents, retinoic acid is generally used for neuron differentiation studies $(3,6,12)$. Previous studies have demonstrated that retinoic acid can induce NT2 cells to give rise to cell aggregation, neuron-like morphology and to express neuronal markers (13-15). Although the mechanisms of retinoic acid-induced neuron differentiation in NT2 cells remain to be elucidated, it has been reported that retinoic acid induced NT2 cells to differentiate into neural cells via Wnt, Nitric oxide and cGMP signal pathways $(16,17)$.

Many ribonucleases have been demonstrated to have anticancer activities (18-21). RC-RNase and onconase are frog ribonucleases purified from Rana catesbeiana and Rana pipiens, respectively. Both belong to the RNase A superfamily (22-25). RC-RNase and onconase exert cytotoxic effects on various cancer cells such as hepatoma, cervical cancer, breast cancer, leukemia, mesothelioma, lung cancer, lymphoma, myeloma and prostate carcinoma (21,26-31). Although the mechanisms of frog ribonuclease-exerted cytotoxicity remain to be elucidated, it is noteworthy that 
onconase has been used as an anticancer drug in clinical trails (32-35). Previous studies indicated that RC-RNase and onconase exert different cytotoxic effects in different cancer cell types $(28,30,31,36-41)$. In addition, several studies suggested that RC-RNase- and onconase-induced cell cytotoxicity may be related to the caspase cascade and MAPK signal pathway $(36,38,42-44)$. Similar to RC-RNase, RC-6 (Rana catesbeiana ribonuclease-6) is also a frog ribonuclease derived from Rana catesbeiana $(29,45)$. Previous studies demonstrated that onconase and RC-RNase can induce cell death in various cancer cells $(21,26-31)$. However, only few studies showed that RC- 6 inhibited cell growth in cervical cancer and hepatoma cells $(29,45)$. Therefore, whether RC-6 can exert anticancer activities in various cancer cell types and the mechanisms of RC-6-induced cytotoxic effects on cancer cells remain unclear. In addition, to date, there are no studies to demonstrate whether frog ribonucleases (RC-RNase, onconase, RC-6) can inhibit cell growth in embryonal carcinoma cells.

Here, RC-6-induced anticancer effects on NT2 cells were investigated. The present study demonstrated that RC-6 can inhibit cell growth and induce caspase-9/-3 cascade activation in NT2 cells. On the other hand, some NT2 cells remained alive after RC-6 treatment. Of note, these remaining live cells displayed cell aggregation and neuron-like morphology similar to retinoic acid-differentiated NT2 cells. However, when we compared RC-6-treated NT2 cells with retinoic acid-treated NT2 cells, neuron marker was found in retinoic acid-treated NT2 cells but not in RC-6-treated NT2 cells. In addition, senescence characteristics were observed in a small fraction of NT2 cells after RC- 6 treatment. Taken together, our study is the first to indicate that RC-6 can induce caspase-9/-3 activities and senescence characteristics in NT2 cells and it can also induce cell aggregation, neuron-like morphology in the remaining live cells.

\section{Materials and methods}

Materials. RC-6 was kindly provided by Dr Jaang-Jiun Wang (Division of Pediatric Infectious Diseases, Emory University School of Medicine, Atlanta, GA, USA). p16 and Tau antibodies were purchased from BD Biosciences (San Jose, CA, USA). p21 and p27 antibodies were bought from Santa Cruz Biotechnology (Santa Cruz, CA, USA). Horseradish peroxidase-conjugated secondary antibodies were from Sigma-Aldrich (St. Louis, MO, USA). FITCconjugated secondary antibody was obtained from Jackson ImmunoResearch (West Grove, PA, USA). Ac-LEHD-pNA (acetyl-Leu-Glu-His-Asp-p-nitroanilide; caspase-9 substrate), Ac-DEVD-pNA (Acetyl-Asp-Glu-Val-Asp-p-nitroanilide; caspase-3-like substrate), and Ac-IETD-pNA (acetyl-Ile-GluThr-Asp-p-nitroanilide; caspase- 8 substrate) were purchased from AnaSpec (San Jose, CA, USA). Fetal bovine serum, DMEM, non-essential amino acid, L-glutamine and penicillin/streptomycin were purchased from Gibco-BRL.

Cell lines and cell cultures. The NT2 cell line was obtained from Bioresources Collection and Research Center (BCRC, Hsinchu, Taiwan). NT2 cells were cultured in DMEM supplemented with $10 \%$ fetal bovine serum, $2 \mathrm{mM}$ L-glutamine,

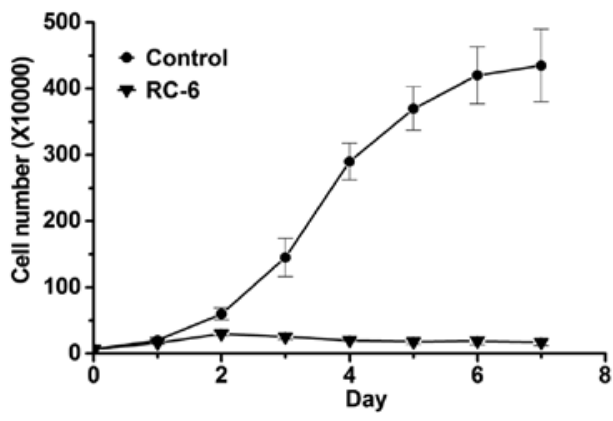

Figure 1. RC-6 inhibits cell growth in NT2 cells. Data were obtained from four triplicate groups and are displayed as means \pm SD

$100 \mathrm{IU} / \mathrm{ml}$ penicillin/streptomycin, and $0.1 \mathrm{mM}$ non-essential amino acids and maintained at $37^{\circ} \mathrm{C}$ in a humidified atmosphere containing $5 \% \mathrm{CO}_{2}$.

Cell viability assay. Cell viability assay was performed as previously described $(31,44)$. In brief, cells were grown on 6 -well cell culture plates overnight. After $24 \mathrm{~h}$, cells were treated with $50 \mu \mathrm{g} / \mathrm{ml} \mathrm{RC}-6$ (experimental group) or without RC-6 (control group). Every $24 \mathrm{~h}$, cells were collected and stained with trypan blue and counted on a hemocytometer.

Caspase substrate cleavage assay. Caspase activities were determined using caspase substrate cleavage assay $(31,44)$. Briefly, cells were lysed with lysis buffer $(50 \mathrm{mM}$ Tris- $\mathrm{HCl}$, $120 \mathrm{mM} \mathrm{NaCl}, 1 \mathrm{mM}$ EDTA, 1\% NP-40, pH 7.5) and were then treated with protease inhibitors. Subsequently, cell pellets were cleaned through centrifugation $\left(15,000 \mathrm{x} \mathrm{g}\right.$, at $4^{\circ} \mathrm{C}$, for $\left.30 \mathrm{~min}\right)$. Caspase-3, -8 and -9 activities were determined. The working solutions were prepared involving experimental sample $(80 \mu \mathrm{g}$ total protein), $158 \mu \mathrm{l}$ reaction buffer (20\% glycerol, $0.5 \mathrm{mM}$ EDTA, $5 \mathrm{mM}$ dithiothreitol, $100 \mathrm{mM}$ HEPES, pH 7.5), and $2 \mu \mathrm{l}$ fluorogenic substrate (Ac-LEHD-pNA, Ac-DEVD-pNA or Ac-IETD-pNA). Then, the working solutions were incubated for $8 \mathrm{~h}$ at $37^{\circ} \mathrm{C}$. The fluorogenic substrate was determined at $405 \mathrm{~nm}$ in an ultra-microplate reader (Bio-Tek Instruments). Fold increase in caspase activity was calculated using the following formula: (A405 sample - A405 $5_{\text {control }}$ )/A405

Senescence-associated $\beta$-galactosidase (SA- $\beta$-Gal) assay. SA- $\beta$-gal activity was assessed as described in a previous study (46). In brief, cells were fixed with $0.5 \%$ glutaraldehyde solution for $15 \mathrm{~min}$. Next, cells were treated with $0.02 \% \mathrm{NP}-40$ and $0.1 \%$ sodium deoxycholate for $15 \mathrm{~min}$. Then, cells were incubated with $1 \mathrm{mg} / \mathrm{ml} \mathrm{X-gal} \mathrm{substrate} \mathrm{solution} \mathrm{(5-bromo-}$ 4-chloro-3-indolyl-bd-galactopyranoside) containing $5 \mathrm{mM}$ potassium ferricyanide and $2 \mathrm{mM}$ magnesium chloride at an acidic $\mathrm{pH} 6.0$ for $16 \mathrm{~h}$ under $\mathrm{CO}_{2}$-free and dark conditions.

Western blot assay. Cells were treated with lysis buffer (50 mM Tris-HCl, $120 \mathrm{mM} \mathrm{NaCl}, 1 \mathrm{mM}$ EDTA, 1\% NP-40 and $\mathrm{pH} 7.5)$. After centrifugation, $(16,000 \mathrm{xg})$ at $4^{\circ} \mathrm{C}$ for $10 \mathrm{~min}$, the suspension fraction containing protein was collected. The protein concentration of the cell lysates was measured with a Bio-Rad protein assay kit (Bio-Rad Laboratories) according to the manufacturer's instructions. Next, proteins were sepa- 

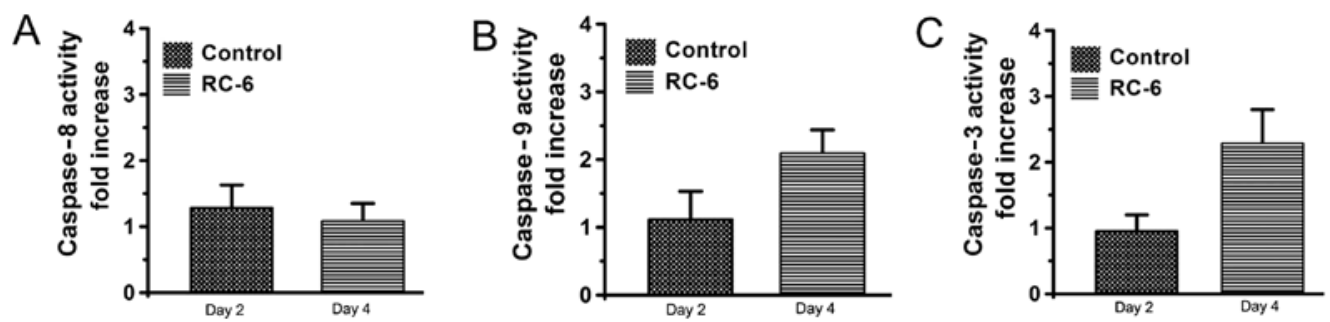

Figure 2. Caspase-9 and -3 activities are induced with RC-6 treatment. (A) Caspase-8, (B) caspase-9 and (C) caspase-3 activities were measured in RC-6treated cells. Data were determined from four triplicate groups and are displayed as means $\pm \mathrm{SD}$.
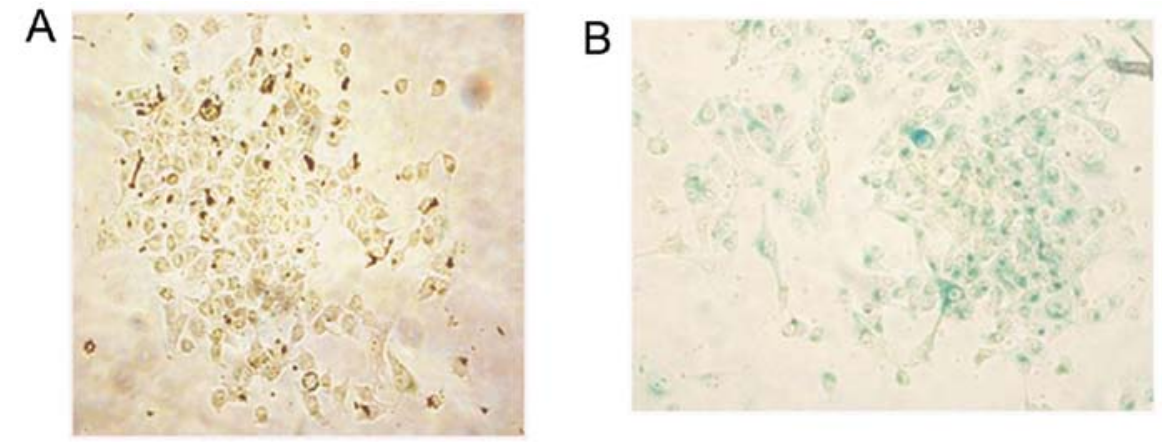

Figure 3. RC-6 induces senescence-associated $\beta$-galactosidase activity. $\beta$-galactosidase activity was determined in (A) control and (B) RC-6-treated cells. Note that blue color was found in RC-6-treated cells.

rated by $13.3 \%$ SDS-PAGE and transferred to polyvinylidene difluoride membranes (Millipore, Billerica, MA, USA). The membranes were blocked with $5 \%$ skim milk for $4 \mathrm{~h}$ at room temperature then probed with primary antibodies overnight at $4{ }^{\circ} \mathrm{C}$. Membranes were washed three times with $0.1 \%$ Tween-20 (15 min/every time), then incubated with HRP-conjugated secondary antibody (1:1,000 dilution) for $2 \mathrm{~h}$ at room temperature. All proteins were observed using Western Lightning Chemiluminescence reagent plus (Perkin-Elmer, Waltham, MA, USA).

Immunofluorescent assay. Cells were fixed with $4 \%$ paraformaldehyde for 15 min then treated with $0.03 \%$ Triton X-100 and blocked with $3 \%$ BSA. The cells were incubated with Tau antibody overnight at $4^{\circ} \mathrm{C}$. After washing three times with PBS (15 min/time), cells were incubated with a secondary goat anti-rabbit FITC antibody at room temperature for $1 \mathrm{~h}$. After washing three times with PBS (15 min/time), the cells were observed under fluorescent microscopy.

Statistical analysis. Data were obtained from four independent triplicate experiments and are presented as the mean values of the chosen triplicate groups. The data are shown as means \pm standard deviations (SD).

\section{Results}

Cell growth inhibition and caspase-9/-3 cascade are induced in NT2 cells with RC-6 treatment. In the present study, whether RC-6 had antitumor effects on NT2 cells was determined by cell number observation. Following RC-6 treatment, viable cells were counted by using cell viability assay with trypan

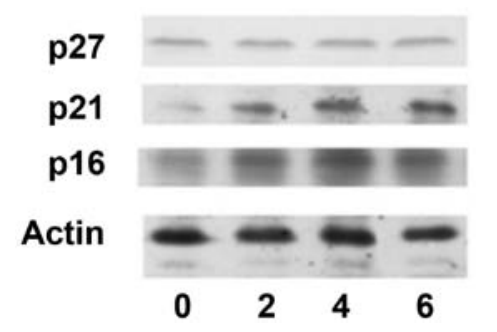

Figure 4. RC-6 induces senescence-associated protein expression. NT2 cells were treated with RC-6 for 0 days (lane 1), 2 days (lane 2), 4 days (lane 3) or 6 days (lane 4). Detection of actin served as internal control. Note that p16 and p27 protein levels were increased, but p27 protein level was not increased.

blue stain under a hemocytometer $(31,44)$. When comparing RC-6-treated cells with control cells, the cell number continuously increased in control cells while cell growth was clearly inhibited in RC-6-treated cells (Fig. 1). In addition, as shown in Fig. 1, there were few remaining live cells after RC-6 treatment on day 7. Next, caspase activation was determined by using substrate cleavage assay $(30,36)$. Our results showed that caspase- $9,-8$ and -3 were not activated in NT2 cells with RC-6 treatment at day 2, whereas caspase- 9 and -3 activities were observed on day 4 (Fig. 2B and C). However, caspase- 8 activity was not clearly found in RC-6-treated cells on day 2 and day 4 (Fig. 2A). These results suggested that RC-6 exerts an antitumor effect in NT2 cells and induces cell cytotoxicity related to the caspase-9/-3 cascade pathway.

Senescence characteristics in NT2 cells after RC-6 treatment. Our observations of cell morphology and cell growth of RC-6-treated cells under a microscope showed that a small 
A
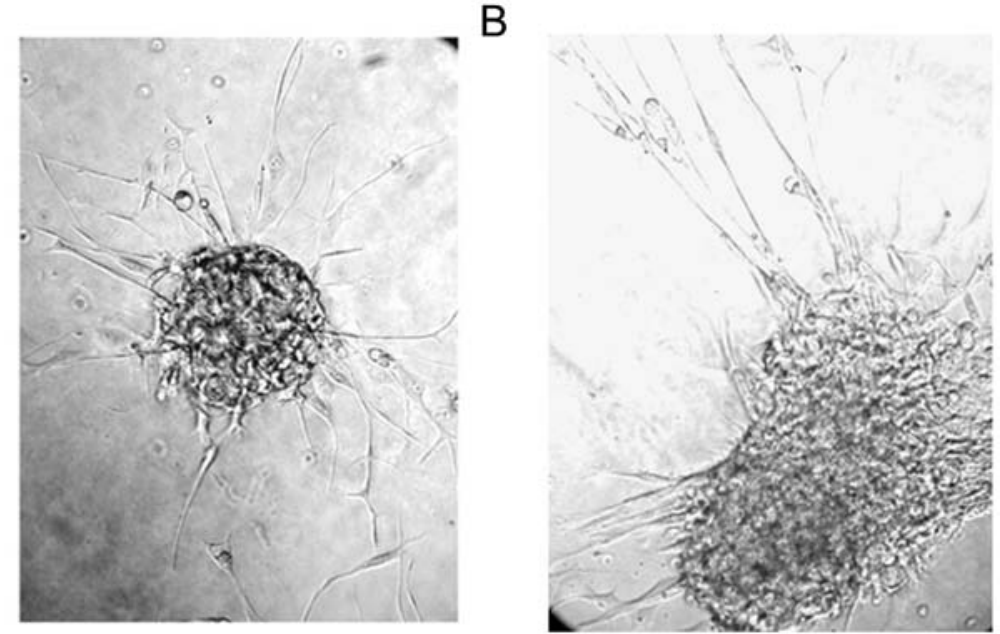

Figure 5. RC-6-induced neuron-like morphology observed under a phase-contrast microscope. (A) RC-6-treated cells and (B) retinoic acid-differentiated cells displayed similar neuron sphere phenotype. Retinoic acid-differentiated cells served as positive control.
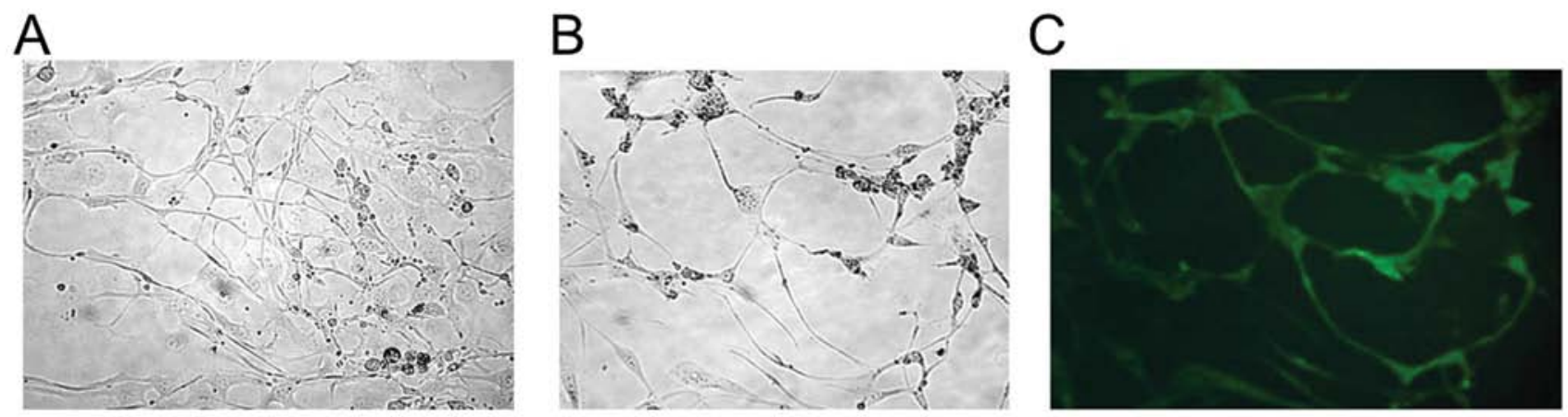

Figure 6. Neuron marker only appeared in retinoic acid-differentiated cells but not in RC-6 induced cells. Neuron marker (Tau) was detected by immunoblotting assay and observed under a fluorescent microscope. (A) RC-6-treated cells and (B) retinoic acid-differentiated cells had similar neuron-like morphology. (C) Tau protein was only found in retinoic acid-differentiated cells. Retinoic acid-differentiated cells served as positive control.

fraction of NT2 cells had flat phenotype and these cells were not able to proliferate similar to cellular senescence as in previous studies (46-49). In order to investigate whether RC-6 induced cellular senescence, SA- $\beta$-Gal assay was performed. Our results showed that some flat, enlarged RC-6-treated cells had SA- $\beta-$ Gal activity which appeared as blue color inside the cells (Fig. 3B). However, blue color was not found in control cells (Fig. 3A). Thus, RC-6 induced some cells to give rise to cellular senescence. Previous studies indicated that p16, p21 and p27 are related to cellular senescence in senescence cells (49-53). Therefore, these proteins were determined in the present study. Western blotting assay (Fig. 4) demonstrated that p16 and p21 levels were increased in RC-6-treated cells whereas p27 level was not increased in RC-6-treated cells. Hence, RC-6 was able to induce p16 and p 21 protein increase and cause cellular senescence in a small fraction of NT2 cells.

Neuron-like morphology in the remaining live cells following RC-6 treatment. After RC-6 treatment for 7 days, most cells died, while few cells survived. These remaining live cells were collected and re-cultured with fresh media under RC-6-free conditions. Notably, the remaining live cells aggregated and presented a neural sphere-like phenotype similar to retinoic acid-differentiated NT2 cells (Fig. 5). Subsequently, the remaining live cells presented a neuron-like morphology (Fig. 6A) similar to retinoic acid-differentiated NT2 cells (Fig. 6B). When comparing the remaining live cells with retinoic acid-differentiated cells, neuron marker Tau only appeared in retinoic acid-differentiated cells (Fig. 6C); however, Tau was not found in the remaining live cells after RC-6 treatment (data not shown). The present study suggests that RC-6 induced NT2 cells to form neuron-like cells whereas these cells did not have neuron function.

\section{Discussion}

RC-6 has been reported to exert anticancer effects on human cervical cancer (HeLa) and hepatoma (HepG2) cells $(29,45)$. In the present study, we further demonstrated that RC-6 also exerted anticancer effects on human embryonal carcinoma cells (NT2 cells). The results suggested that RC-6 may exert anticancer effects on various types of cancer, such as the RC-RNase- and onconase-exerted anticancer effects (21,26-31). Although the mechanisms of RC-6-induced cell cytotoxicity on cervical cancer cells has not been studied (29), RC-6-induced cell cytotoxicity in HepG2 cells was related to 
caspase-9/-3 cascade (45). Here, caspase- 9 and -3 activities were found in RC-6-treated NT2 cells similar to RC-6-treatedHepG2 cells. Thus, we considered that the caspase-9/-3 cascade is an important signal pathway in RC-6-induced cell death. RC-6, RC-RNase and onconase are all frog ribonucleases (22-25). RC-RNase and onconase can induce caspase-9 and -3 activities in cancer cells; however, they cannot induce caspase- 8 activity in cancer cells $(31,36,38,54)$. In the present study, RC- 6 also induced caspase- 9 and -3 activities but did not induce caspase- 8 activity. Based on these findings, we suggested that frog ribonuclease-induced cell death was related to the caspase- $9 /-3$ cascade but not the caspase- $8 /-3$ cascade.

Retinoic acid induces NT2 cells to differentiate into neuron-like cells, as has previously been reported (2,6,55-57). Numerous studies have demonstrated that cell aggregation and neuron-like morphology appear in retinoic acid-differentiated NT2 cells (13-15). Moreover, caspase activities were observed in NT2 cells during retinoic acid treatment $(8,56,58)$. Here, cell aggregation, neuron-like morphology was also observed in the remaining live NT2 cells after RC- 6 treatment. In addition, caspase activities were activated in NT2 cells during RC-6 treatment. Our results indicated that RC-6-treated NT2 cells were similar to retinoic acid-treated NT2 cells. Therefore, we consider that RC-6 and retinoic acid may induce certain similar signal pathways in NT2 cells, whereas these signal pathways are still unknown and remain to be studied in the future. On the other hand, retinoic acid induced neuron marker expression in NT2 cells in the present study as well as in previous studies $(4,13)$. However, neuron markers were not clearly found in RC-6-treated NT2 cells in the present study. A previous study showed that RC-6 having ribonuclease activity could cleave RNAs (29). There is no evidence to show that retinoic acid can induce RNA degradation similar to ribonucleases. Based on these findings, we speculated that neuron marker RNAs may be degraded in NT2 cells during RC- 6 treatment; therefore, neuron markers cannot be found in RC-6-treated NT2 cells unlike retinoic acid-differentiated NT2 cells.

Recent studies demonstrated that senescence can be induced in many cell types under various conditions and treatments such as hypoxia, uremia, UVB, radiation, $\mathrm{H}_{2} \mathrm{O}_{2}$ and oxidized low-density lipoprotein (59-64). Previous studies indicated that $\beta$-galactosidase activity is a major characteristic found in senescence cells and is generally applied to senescence detection (65-67). In addition, many studies have reported that p16 and p21 protein levels are increased in senescence cells (50-53). At present, a small fraction of RC-6-treated NT2 cells can express $\beta$-galactosidase activity. Moreover, p16 and p21 protein levels are increased in RC-6-treated NT2 cells. Thus, our results indicated that RC- 6 can induce senescence characteristics in NT2 cells. Previous studies demonstrated that p27 protein increase was also found in senescence cells $(49,68,69)$. However, p27 protein levels were not increased significantly in RC-6-treated NT2 cells. Our results indicated that p16 and p21 play more important roles than p27 in RC-6-induced senescence.

In summary, the present study is the first to show that RC-6 can induce embryonal carcinoma cells to give rise to caspase-9/-3 activation, senescence characteristics and neuronlike morphology.

\section{Acknowledgements}

The present study was supported by the following grants: NSC99-2320-B-039-030-MY3, NSC99-2632-B-039-001-MY3, NSC101-2321-B-039-004 and NHRI-EX102-10245BI.

\section{References}

1. Biswal BK, Beyrouthy MJ, Hever-Jardine MP, et al: Acute hypersensitivity of pluripotent testicular cancer-derived embryonal carcinoma to low-dose 5-aza deoxycytidine is associated with global DNA damage-associated p53 activation, anti-pluripotency and DNA demethylation. PLoS One 7: e53003, 2012.

2. Coyle DE, Li J and Baccei M: Regional differentiation of retinoic acid-induced human pluripotent embryonic carcinoma stem cell neurons. PLoS One 6: e16174, 2011.

3. Favaedi R, Shahhoseini M and Akhoond MR: Comparative epigenetic analysis of Oct4 regulatory region in RA-induced differentiated NT2 cells under adherent and non-adherent culture conditions. Mol Cell Biochem 363: 129-134, 2012.

4. Tegenge MA, Roloff F and Bicker G: Rapid differentiation of human embryonal carcinoma stem cells (NT2) into neurons for neurite outgrowth analysis. Cell Mol Neurobiol 31: 635-643, 2011.

5. Drakulic D, Krstic A and Stevanovic M: Establishment and initial characterization of SOX2-overexpressing NT2/D1 cell clones. Genet Mol Res 11: 1385-1400, 2012.

6. Jezierski A, Deb-Rinker P, Sodja C, et al: Involvement of NOS3 in RA-Induced neural differentiation of human NT2/D1 cells. J Neurosci Res 90: 2362-2377, 2012.

7. Oz S, Maercker C and Breiling A: Embryonic carcinoma cells show specific dielectric resistance profiles during induced differentiation. PLoS One 8: e59895, 2013.

8. Musch T, Oz Y, Lyko F and Breiling A: Nucleoside drugs induce cellular differentiation by caspase-dependent degradation of stem cell factors. PLoS One 5: e10726, 2010.

9. Tripathi R, Samadder T, Gupta S, Surolia A and Shaha C: Anticancer activity of a combination of cisplatin and fisetin in embryonal carcinoma cells and xenograft tumors. Mol Cancer Ther 10: 255-268, 2011.

10. Chang KS: Down-regulation of c-Ki-ras2 gene expression associated with morphologic differentiation in human embryonal carcinoma cells treated with berberine. J Formos Med Assoc 90: 10-14, 1991.

11. Skladchikova G, Berezin V and Bock E: Valproic acid, but not its non-teratogenic analogue 2-isopropylpentanoic acid, affects proliferation, viability and neuronal differentiation of the human teratocarcinoma cell line NTera-2. Neurotoxicology 19: 357-370, 1998.

12. Kakhki SA, Shahhoseini M and Salekdeh GH: Comparative SRY incorporation on the regulatory regions of pluripotency/differentiation genes in human embryonic carcinoma cells after retinoic acid induction. Mol Cell Biochem 376: 145-150, 2013.

13. Megiorni F, Mora B, Indovina P and Mazzilli MC: Expression of neuronal markers during NTera2/cloneD1 differentiation by cell aggregation method. Neurosci Lett 373: 105-109, 2005.

14. Jain P, Cerone MA, Leblanc AC and Autexier C: Telomerase and neuronal marker status of differentiated NT2 and SK-N-SH human neuronal cells and primary human neurons. J Neurosci Res 85: 83-89, 2007.

15. Cheung WM, Fu WY, Hui WS and Ip NY: Production of human CNS neurons from embryonal carcinoma cells using a cell aggregation method. Biotechniques 26: 946-954, 1999.

16. Snow GE, Kasper AC, Busch AM, et al: Wnt pathway reprogramming during human embryonal carcinoma differentiation and potential for therapeutic targeting. BMC Cancer 9: 383, 2009.

17. Tegenge MA and Bicker G: Nitric oxide and cGMP signal transduction positively regulates the motility of human neuronal precursor (NT2) cells. J Neurochem 110: 1828-1841, 2009.

18. Ardelt W, Ardelt B and Darzynkiewicz Z: Ribonucleases as potential modalities in anticancer therapy. Eur J Pharmacol 625: 181-189, 2009.

19. Chang CH, Gupta P, Michel R, et al: Ranpirnase (frog RNase) targeted with a humanized, internalizing, anti-Trop-2 antibody has potent cytotoxicity against diverse epithelial cancer cells. Mol Cancer Ther 9: 2276-2286, 2010. 
20. Fang EF and Ng TB: Ribonucleases of different origins with a wide spectrum of medicinal applications. Biochim Biophys Acta 1815: 65-74, 2011.

21. Zwolinska M and Smolewski P: Onconase: a ribonuclease with antitumor activity. Postepy Hig Med Dosw (Online) 64: 58-66, 2010 (In Polish).

22. Chang CF, Chen C, Chen YC, Hom K, Huang RF and Huang TH: The solution structure of a cytotoxic ribonuclease from the oocytes of Rana catesbeiana (bullfrog). J Mol Biol 283: 231-244, 1998.

23. Gahl RF, Narayan M, Xu G and Scheraga HA: Dissimilarity in the oxidative folding of onconase and ribonuclease A, two structural homologues. Protein Eng Des Sel 21: 223-231, 2008.

24. Gahl RF and Scheraga HA: Oxidative folding pathway of onconase, a ribonuclease homologue: insight into oxidative folding mechanisms from a study of two homologues. Biochemistry 48 2740-2751, 2009

25. Rosenberg HF, Zhang J, Liao YD and Dyer KD: Rapid diversification of RNase A superfamily ribonucleases from the bullfrog, Rana catesbeiana. J Mol Evol 53: 31-38, 2001

26. Ita M, Halicka HD, Tanaka T, et al: Remarkable enhancement of cytotoxicity of onconase and cepharanthine when used in combination on various tumor cell lines. Cancer Biol Ther 7 : 1104-1108, 2008

27. Lee I: Ranpirnase (Onconase), a cytotoxic amphibian ribonuclease, manipulates tumour physiological parameters as a selective killer and a potential enhancer for chemotherapy and radiation in cancer therapy. Expert Opin Biol Ther 8: 813-827, 2008

28. Hu CC, Lee YH, Tang CH, Cheng JT and Wang JJ: Synergistic cytotoxicity of Rana catesbeiana ribonuclease and IFN- $\gamma$ on hepatoma cells. Biochem Biophys Res Commun 280: 1229-1236, 2001.

29. Liao YD, Huang HC, Leu YJ, Wei CW, Tang PC and Wang SC: Purification and cloning of cytotoxic ribonucleases from Rana catesbeiana (bullfrog). Nucleic Acids Res 28: 4097-4104, 2000.

30. Yiang GT, Yu YL, Chou PL, et al: The cytotoxic protein can induce autophagocytosis in addition to apoptosis in MCF-7 human breast cancer cells. In Vivo 26: 403-409, 2012.

31. Wei CW, Hu CC, Tang $\mathrm{CH}$, Lee MC and Wang JJ: Induction of differentiation rescues HL-60 cells from Rana catesbeiana ribonuclease-induced cell death. FEBS Lett 531: 421-426, 2002.

32. Costanzi J, Sidransky D, Navon A and Goldsweig H: Ribonucleases as a novel pro-apoptotic anticancer strategy: review of the preclinical and clinical data for ranpirnase. Cancer Invest 23 643-650, 2005

33. Mikulski S, Grossman A, Carter P, Shogen K and Costanzi J: Phase I human clinical trial of ONCONASE ${ }^{\mathbb{B}^{*}}$ (P-30 protein) administered intravenously on a weekly schedule in cancer patients with solid tumors. Int J Oncol 3: 57-64, 1993.

34. Mikulski SM, Costanzi JJ, Vogelzang NJ, et al: Phase II trial of a single weekly intravenous dose of ranpirnase in patients with unresectable malignant mesothelioma. J Clin Oncol 20: 274-281, 2002.

35. Vogelzang NJ, Aklilu M, Stadler WM, Dumas MC and Mikulski SM: A phase II trial of weekly intravenous ranpirnase (Onconase), a novel ribonuclease in patients with metastatic kidney cancer. Invest New Drugs 19: 255-260, 2001.

36. Tang CH, Hu CC, Wei CW and Wang JJ: Synergism of Rana catesbeiana ribonuclease and IFN- $\gamma$ triggers distinct death machineries in different human cancer cells. FEBS Lett 579 265-270, 2005

37. Tseng HH, Yu YL, Chen YL, et al: RC-RNase-induced cell death in estrogen receptor positive breast tumors through downregulation of Bcl-2 and estrogen receptor. Oncol Rep 25: 849-853, 2011

38. Grabarek J, Ardelt B, Du L and Darzynkiewicz Z: Activation of caspases and serine proteases during apoptosis induced by onconase (Ranpirnase). Exp Cell Res 278: 61-71, 2002.

39. Halicka HD, Ardelt B, Shogen K and Darzynkiewicz Z: Mild hyperthermia predisposes tumor cells to undergo apoptosis upon treatment with onconase. Int J Oncol 30: 841-847, 2007.

40. Michaelis M, Cinatl J, Anand P, et al: Onconase induces caspaseindependent cell death in chemoresistant neuroblastoma cells. Cancer Lett 250: 107-116, 2007.

41. Ramos-Nino ME, Vianale G, Sabo-Attwood T, et al: Human mesothelioma cells exhibit tumor cell-specific differences in phosphatidylinositol 3-kinase/AKT activity that predict the efficacy of Onconase. Mol Cancer Ther 4: 835-842, 2005.
42. Iordanov MS, Wong J, Newton DL, et al: Differential requirement for the stress-activated protein kinase/c-Jun NH(2)-terminal kinase in RNAdamage-induced apoptosis in primary and in immortalized fibroblasts. Mol Cell Biol Res Commun 4: 122-128, 2000.

43. Altomare DA, Rybak SM, Pei J, et al: Onconase responsive genes in human mesothelioma cells: implications for an RNA damaging therapeutic agent. BMC Cancer 10: 34, 2010.

44. Yiang GT, Yu YL, Hu SC, Chen MH, Wang JJ and Wei CW: PKC and MEK pathways inhibit caspase-9/-3-mediated cytotoxicity in differentiated cells. FEBS Lett 582: 881-885, 2008

45. Wei CW, Chou PL, Hung YT and Yiang GT: Synergistic cytotoxicity of 1,3-bis(2-chloroethyl)-1-nitrosourea and Rana catesbeiana ribonuclease- 6 in hepatoma cells. Tzu Chi Med J 23: 9-15, 2011.

46. Hu Z, Gu Y, Han B, et al: Knockdown of AGR2 induces cellular senescence in prostate cancer cells. Carcinogenesis 33: 1178-1186, 2012.

47. Giovannini C, Gramantieri L, Minguzzi M, et al: CDKN1C/P57 is regulated by the Notch target gene Hesl and induces senescence in human hepatocellular carcinoma. Am J Pathol 181: 413-422, 2012

48. Leontieva OV, Natarajan V, Demidenko ZN, Burdelya LG, Gudkov AV and Blagosklonny MV: Hypoxia suppresses conversion from proliferative arrest to cellular senescence. Proc Natl Acad Sci USA 109: 13314-13318, 2012.

49. Ewald JA, Desotelle JA, Church DR, et al: Androgen deprivation induces senescence characteristics in prostate cancer cells in vitro and in vivo. Prostate 73: 337-345, 2013

50. Burns TF, Dobromilskaya I, Murphy SC, et al: Inhibition of TWIST1 leads to activation of oncogene-induced senescence in oncogene-driven non-small cell lung cancer. Mol Cancer Res 11: 329-338, 2013

51. Tu Z, Zhuang X, Yao YG and Zhang R: BRG1 is required for formation of senescence-associated heterochromatin foci induced by oncogenic RAS or BRCA1 loss. Mol Cell Biol 33: 1819-1829, 2013.

52. Capparelli C, Chiavarina B, Whitaker-Menezes D, et al: CDK inhibitors (p16/p19/p21) induce senescence and autophagy in cancer-associated fibroblasts, 'fueling' tumor growth via paracrine interactions, without an increase in neo-angiogenesis. Cell Cycle 11: 3599-3610, 2012.

53. Wu X, Jia S, Zhang X, Si X, Tang W and Luo Y: Two mechanisms underlying the loss of $\mathrm{p} 16^{\text {Ink4a }}$ function are associated with distinct tumorigenic consequences for WS MEFs escaping from senescence. Mech Ageing Dev 133: 549-555, 2012.

54. Iordanov MS, Ryabinina OP, Wong J, et al: Molecular determinants of apoptosis induced by the cytotoxic ribonuclease onconase: evidence for cytotoxic mechanisms different from inhibition of protein synthesis. Cancer Res 60: 1983-1994, 2000.

55. Kvissel AK, Orstavik S, Oistad P, Rootwelt T, Jahnsen $\mathrm{T}$ and Skalhegg BS: Induction of $C \beta$ splice variants and formation of novel forms of protein kinase A type II holoenzymes during retinoic acid-induced differentiation of human NT2 cells. Cell Signal 16: 577-587, 2004.

56. Patel NA, Song SS and Cooper DR: PKC $\delta$ alternatively spliced isoforms modulate cellular apoptosis in retinoic acid-induced differentiation of human NT2 cells and mouse embryonic stem cells. Gene Expr 13: 73-84, 2006.

57. Misiuta IE, Saporta S, Sanberg PR, Zigova T and Willing AE Influence of retinoic acid and lithium on proliferation and dopaminergic potential of human NT2 cells. J Neurosci Res 83: 668-679, 2006.

58. Pistritto G, Papaleo V, Sanchez P, Ceci C and Barbaccia ML: Divergent modulation of neuronal differentiation by caspase-2 and -9. PLoS One 7: e36002, 2012.

59. Zhang XP, Zhang GH, Wang YY, et al: Oxidized low-density lipoprotein induces hematopoietic stem cell senescence. Cell Biol Int 37: 940-948, 2013.

60. Carracedo J, Buendia P, Merino A, et al: Cellular senescence determines endothelial cell damage induced by uremia. Exp Gerontol 48: 766-773, 2013.

61. Kim HD, Yu SJ, Kim HS, et al: IL-4 induces senescence in human renal carcinoma cell lines through STAT6 and p38 MAPK. J Biol Chem 288: 28743-28754, 2013.

62. Luo H, Yount C, Lang H, et al: Activation of p53 with Nutlin-3a radiosensitizes lung cancer cells via enhancing radiation-induced premature senescence. Lung Cancer 81: 167-173, 2013. 
63. Suo R, Zhao ZZ, Tang ZH, et al: Hydrogen sulfide prevents $\mathrm{H}_{2} \mathrm{O}_{2}$-induced senescence in human umbilical vein endothelial cells through SIRT1 activation. Mol Med Rep 7: 1865-1870, 2013.

64. Mo J, Sun B, Zhao X, et al: Hypoxia-induced senescence contributes to the regulation of microenvironment in melanomas. Pathol Res Pract 209: 640-647, 2013.

65. Bassaneze V, Miyakawa AA and Krieger JE: Chemiluminescent detection of senescence-associated $\beta$ galactosidase. Methods Mol Biol 965: 157-163, 2013.

66. Pospelova TV, Chitikova ZV and Pospelov VA: An integrated approach for monitoring cell senescence. Methods Mol Biol 965: 383-408, 2013
67. Mortuza R, Chen S, Feng B, Sen S and Chakrabarti S: High glucose induced alteration of SIRTs in endothelial cells causes rapid aging in a $\mathrm{p} 300$ and $\mathrm{FOXO}$ regulated pathway. PLoS One 8: e54514, 2013.

68. Diep CH, Charles NJ, Gilks CB, Kalloger SE, Argenta PA and Lange CA: Progesterone receptors induce FOXO1-dependent senescence in ovarian cancer cells. Cell Cycle 12: 1433-1449, 2013.

69. Wang H, Xu Y, Fang Z, Chen S, Balk SP and Yuan X: Doxycycline regulated induction of AKT in murine prostate drives proliferation independently of $\mathrm{p} 27$ cyclin dependent kinase inhibitor downregulation. PLoS One 7: e41330, 2012. 